\title{
Comparison of the effects of TENS stimulation and water immersion on relieving labour pain suffered byprimiparas
}

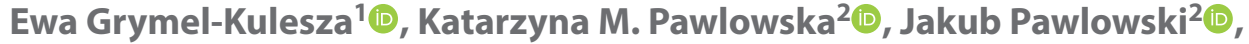 \\ Agnieszka Grochulska² ${ }^{2}$, Marcelina Belkius ${ }^{3}$, Izabela Jerzak ${ }^{4}$ \\ ${ }^{1}$ Gdansk Collage of Health, Poland \\ ${ }^{2}$ Department of Physiotherapy and Wellness, Institute of Health Sciences, Pomeranian University in Slupsk, Poland \\ ${ }^{3}$ Praxis Physiotherapie Jeske, Berlin, Germany \\ ${ }^{4}$ Department of Pharmacology and Toxicology, University of Zielona Gora, Collegium Medicum, Poland
}

\begin{abstract}
Objectives: The aim of this study was to compare pain suffered by primiparas when delivering a child in a traditional way with deliveries where either TENS stimulation or water immersion was used.

Material and methods: Primiparas were divided into 3 groups. In group 1 there were 45 women for whom TENS stimulation was applied during delivery. Group 2 consisted of 38 women who remained in the water during the actual birth of the baby. Group 3 served as the control group and was composed of 32 women. The intensity of pain during delivery was assessed by means of a numerical scale. During the first delivery period, pain was assessed three times at cervical dilation of 2,3 and 4 fingers.

Results: The analysis of pain suffered by primiparas at 2-finger widening showed no statistically significant differences between the groups. However, the analysis of pain experienced at 3-finger opening showed significant differences between the group of women using TENS stimulation in comparison with the control group. When comparing pain at 4-finger opening, statistically significant differences were found between the group of women who delivered in water in comparison to both the control group and the group using TENS stimulation.

Conclusions: TENS stimulation and water immersion are good methods to relieve labour pain; particularly helpful in the first period of labour. They are also safe, alternative, non-pharmacological methods of reducing labour pain.
\end{abstract}

Key words: TENS; water immersion; delivery pain; physiological delivery

Ginekologia Polska 2021; 92, 7: 512-517

\section{INTRODUCTION}

Hydrotherapy has been used since the times of the ancient Greeks and ancient Romans as a natural means of relieving birth pain. In more recenttimes, in Europe in the 1970s, Michael Odent was a great proponentof water immersion. During childbirth, women can enjoy full immersion in a bath, pool or shower [1]. The warming effect during bathing reduces the pain of childbirth by increasing the production of oxytocin, which in turn contributes to the reduction of pain receptors. In addition, warm water calms the woman down, reducing her pain [2].

Transcutaneous Electrical Nerve Stimulation (TENS) is one of the most commonly used neuromodulation tech- niques used in physiotherapy for reducing pain. It is applied for the treatment ofboth acute and chronic pain syndromes [3]. The analgesic effect of TENS is based on the theory of pain inhibition, derived from the control gate theory according to Melzack and Wall 1965 and on central pain inhibition. Animal studies indicate that all three types of opioids (endorphins, enkephalins and dynorphins) are triggered during TENS stimulation regardless of the type of frequency. However, the frequency of the current affects the advantage of producing certain opioids. BURST electrostimulation increases blood endorphin levels up to 3.5 times [6]. High-frequency TENS, on the other hand, triggers greater production of enkephalins and dynorphins [4]. Application

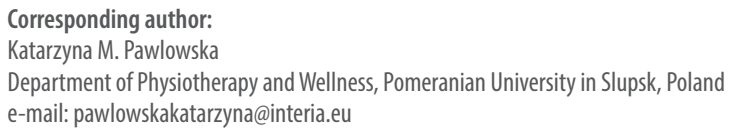


of electrical current during labour does not burden the body, nor does itexpose either mother or foetus to any threat [4-6].

\section{Objectives}

The aim of the study is to compare pain experienced by primiparas during a physiological delivery taking place in a traditional way withdeliveries where TENS stimulation or water immersion was used.

\section{MATERIAL AND METHODS}

The research was conducted from March 2010 to October 2012 in the Maternity Clinic of the Medical University of Gdańsk Clinical Hospital in Gdańsk and in the Francis Żaczek Independent Public Health Care Center in Puck, both in northern Poland. The research was approved by the bioethics commission of Gdansk on $12^{\text {th }}$ January 2010. Beforebeing subject tothe tests, every patient was informed about the purpose of the tests and about the way they were to be carried out. They then read and signed the Patient Information and the Conscious Consent to Participate in the Clinical Study.

After meeting the study participation criteria, the patients were divided into three groups. The patients were assignedarbitrarily to groups 1 and 3 in a non-random way and both groups were divided between Gdansk and Puck (afterthe homogeneity of both groups was confirmed).

Group 2 consisted of arbitrary, non-randomly selected patients allocated to the Puck hospital, because only that hospital had the facilities to deliver in water.

Criteria for joining the tests:

- healthy, full-term pregnancy - at least the $38^{\text {th }}$ week of pregnancy

- correct positioning of the foetus

- cervical dilation at the start of the study of up to $4 \mathrm{~cm}$

- spontaneous delivery

- no contraindications to the use of TENS stimulation in group 1 or water immersion in group 2

- patient's consentto testparticipation

Exclusion criteria:

- lack of patient's consent

- application of pharmacological methods of reducing labour pain in the form of epidural, spinal, Dolargan or nitrous oxide

- delivery by Caesarean section

Patients giving birth for the first time were divided into three groups:

Group 1-45 women who were subject to TENS during delivery.

Group 2-38 women who were subject towater immersion during delivery.

Group 3-32 women who were not subject to eitherTENS or water immersion, as a control group.
During delivery, the intensity of pain was assessed using a numerical scale combined with a descriptive scale where 0 indicatedno pain and 10 indicated unbearable pain. During the first delivery period, pain was recordedthree times when the cervix wasopen at 2, 3 and 4 fingers (i.e., 4, 6 and $8 \mathrm{~cm})$. Pain in the second delivery periodwas assessed immediately after delivery.

Water immersion during childbirth wasonly available in Puck. Women were introduced into the deliverybathtub at the time they had cervical dilation from 3 to $9 \mathrm{~cm}$ (average $6 \mathrm{~cm}$ ). A single stay in the bathtub lasted approx. $60 \mathrm{~min}-$ utes. A 30-minute CTG test was performed before water immersion. During water immersion, foetal heart rate was tested after each contractionby means of a portable heart rate detector. The water level was up to the primipara's umbilicus and the water temperature was $37^{\circ} \mathrm{C}$.

The TENS delivery procedure was carried out by means of a two-channel Neuro Track Obstetric TMTENS electrostimulator by Verity Medical LTD (Fig. 1). The Axelgaard ValuTrode LITEby Axelgaard manufacturing Co. self-adhesive disposable electrodes measuring $4.5 \times 9.5 \mathrm{~cm}$ were used. The electrodes were covered with gel in the MultiStick ${ }^{\circledast}$ Gel technique.

In the first period of delivery, two electrodes were glued to the patient's back at the height of Th10-L2 (Fig. 2). In the event of sacral pains, a second pair of electrodes was glued onto the segment S2-S4 of the spine. At the end of the first delivery period, the electrodes were transferred to the S2-S4 segment of the spine (Fig. 3).

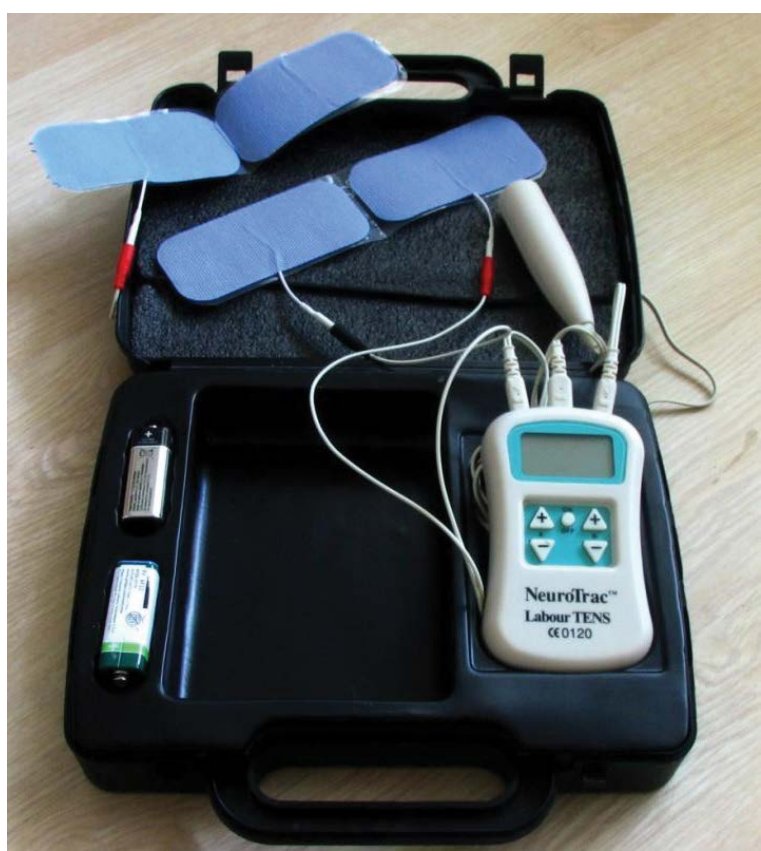

Figure 1. Neuro Track Labour TENS Electrostimulator together with electrodes (own source) 


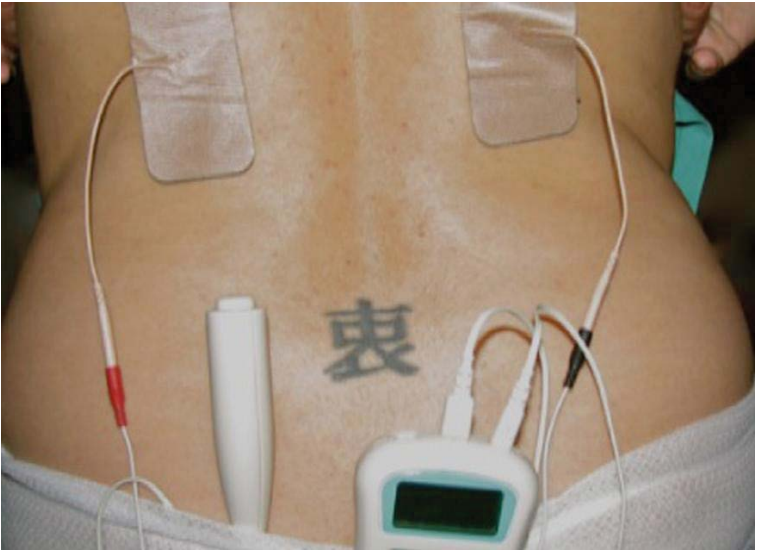

Figure 2. Positioning of electrodes during the first period of labour (own source)

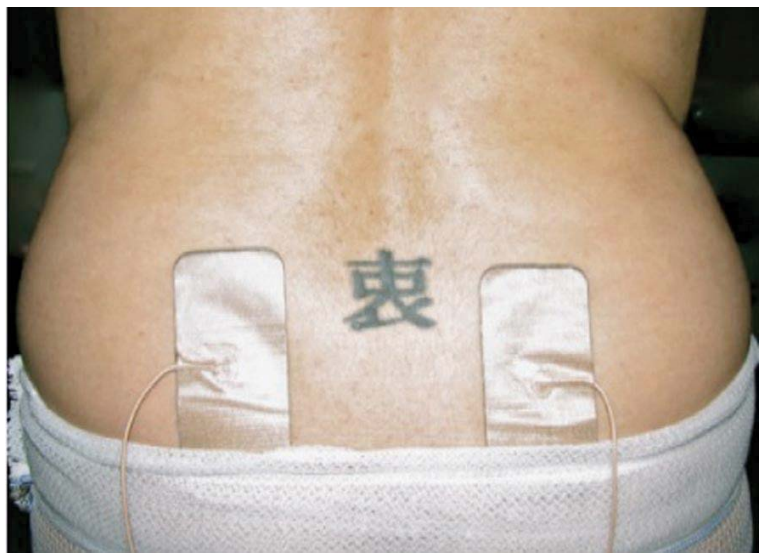

Figure 3. Positioning of electrodes during the second period of labour (own source)

\begin{tabular}{l|l|c|c|c|c|}
\hline \multicolumn{2}{|l|}{ Table 1. Characteristics of studied patients } \\
\hline & ¿observationn & Age (range) & Age $\overline{\mathbf{x}}$ & Week of pregnancy (range) & Week of pregnancy $\overline{\mathbf{x}}$ \\
\hline Group 1 (TENS) & 45 & $18-39$ & 29 & $38-42$ & 40.31 \\
\hline Group 2 (immersion) & 38 & $20-34$ & 25 & $38-42$ & 40.61 \\
\hline Group 3 (control) & 32 & $19-38$ & 28 & $38-42$ & 40.16
\end{tabular}

TENS - Transcutaneous Electrical Nerve Stimulation

At the beginning of the stimulation, the electrostimulator was operated by a physiotherapist. The accompanying person in the delivery room and/or the primipara was then instructed how to operate the electrostimulator.

The electrostimulator generated a current with rectangular, asymmetrical, biphasic pulses. Two current programs were used for the stimulation. During labour contractions, $90 \mathrm{~Hz}$ current with apulse width of $220 \mu$ s was used.

During the break between contractions, BURST current was applied. This stimulation is characterised by the appearance of a high frequency $(150 \mathrm{~Hz})$ pulse wave twice a second with a pulse width of $200 \mu \mathrm{s}$. The intensity of the current was adjusted by the primipara.Stimulation was supposed to cause a strong sensation of tingling or hitting, but without feeling pain or discomfort.

The electrical stimulation started atthe cervix opening of $4 \mathrm{~cm}$ or less and continued until the end of delivery. During the session, the patient could move around the room, jump on a ball or lie down. When using the toilet or shower, the electrostimulator was disconnected, but these breaks were not longer than 30 minutes. During gynaecological examination and cardiotocographic (CTG) recording of the patient, the electrostimulator was turned on.

One-way analysis of variance (ANOVA) was used to comparethe test results. If significant, a post-hoc test Scheffe test was performed. The STATISTICA packagewas used for all analyses.

\section{RESULTS}

The characteristics of the studied groups are presented in Table 1.

The mean, standard deviation, and theminimum and maximum of the intensity of painsuffered by primaparas in TENS, water immersion, and control groups, depending on the degree of dilation and during the second stage of labour are shown in Table 2.

In primiparas with 2-finger dilation,the analysis ofpain results indicatedthat there were no statistically significant differences between the group means (Tab. 3). However, the analysis of pain results for 3-finger opening showed significant differences between the means forthe group of women using TENS and for the control group; women using TENS rated their mean pain 1 unit lower than women from the control group (Tab. 4). When comparing pain at 4-finger opening, statistically significant differences were found between the group subject to immersion and both the control and TENS groups (Tab. 5). The mean rate indicated by thepatients from the control group was 8.72 , that for TENS was 7.76 while the mean for patients giving birth in water was 6.71 (Tab. 6). 


\begin{tabular}{|l|c|c|c|c|}
\hline \multicolumn{6}{|l|}{ Table 2. Characteristics of the pain intensity in primiparas at particular stages of delivery } \\
\hline Pain during: & Opening at $\mathbf{2}$ fingers & Opening at $\mathbf{3}$ fingers & Opening at $\mathbf{4}$ fingers & In the second stage of labour \\
\hline$\tilde{\bar{\chi}}$ TENS & 4.16 & 5.62 & 7.76 & 8.13 \\
\hline$\tilde{\tilde{\chi}}$ immersion & 3.92 & 6.03 & 6.71 & 7.11 \\
\hline$\tilde{\bar{\chi}}$ control & 4.78 & 6.72 & 8.72 & 7.34 \\
\hline Min TENS & 0 & 1 & 2 & 2 \\
\hline Min immersion & 0 & 4 & 4 & 2 \\
\hline Min control & 2 & 3 & 4 & 2 \\
\hline Max TENS & 10 & 10 & 10 & 10 \\
\hline Max immersion & 9 & 10 & 10 & 10 \\
\hline Max control & 9 & 10 & 10 & 10 \\
\hline SD TENS & 2.13 & 1.85 & 1.88 & 2.22 \\
\hline SD immersion & 1.98 & 1.68 & 1.54 & 2.13 \\
\hline SD & 1.74 & 1.82 & 1.61 & 2.44 \\
\hline
\end{tabular}

TENS — Transcutaneous Electrical Nerve Stimulation; SD — standard deviation

Pain assessment for the second stage of labour showed no statistically significant differences between the groups (Tab. 2).

\section{DISCUSSION}

One of the basic purposesof the current study was to determine the degree of pain reduction as a result of applying TENS stimulation or water immersion relative to the patients in the control group, and with each other.

Birth pain, as previously shown, depends on many factors, both physical and mental [2]. Bączyk et al. [7], basedon their own research, stated that women were most afraid of their health, the health of their babies, and well-being after delivery. However, the main source of fear was severe birth pain (93.8\% of respondents).

Pain assessment is also very difficult. It depends on the patient's mental characteristics and tends to be very subjective. It is not possible to objectify the pain assessment. Furthermore, pain relief, despite standardised methods, often does not give the same results to all patients. Various differences between sufferers and theirmental attitudes significantly affect the level of perception of pain [8]. Due to the nature of the currentstudy, a simple and quick method of assessing pain, namely the numerical scale in combination with a descriptive scale was used. Some other researchers also used a similar pain assessment [9-12].

The effectiveness of non-pharmacological methods of reducing pain during labour is less than for pharmacological methods. However, the fact that non-pharmacological methods of decreasing labour pain do not have negative consequences for both the baby and the mother during and after delivery, should be considered. They offer an alternative forpeople who do not want, or cannot take advantage of, pharma-

\begin{tabular}{|c|c|c|c|c|}
\hline & Group & $\{1\}$ & $\{2\}$ & $\{3\}$ \\
\hline 1 & TENS & & 0.865352 & 0.395329 \\
\hline 2 & Immersion & 0.865352 & & 0.198050 \\
\hline 3 & Control & 0.395329 & 0.198050 & \\
\hline
\end{tabular}

Table 4. Scheffe Test. Pain when opening at 3 fingers in the
primiparas
\begin{tabular}{|l|c|c|c|c|}
\hline & Group & $\{1\}$ & $\{2\}$ & $\{3\}$ \\
\hline 1 & TENS & & 0.592291 & $0.033004^{*}$ \\
\hline 2 & Immersion & 0.592291 & & 0.275860 \\
\hline 3 & Control & $0.033004^{*}$ & 0.275860 & \\
\hline
\end{tabular}

\begin{tabular}{|c|c|c|c|c|}
\hline & Group & $\{1\}$ & $\{2\}$ & $\{3\}$ \\
\hline 1 & TENS & & $0.023446^{*}$ & 0.054149 \\
\hline 2 & Immersion & $0.023446^{*}$ & & $0.000018^{*}$ \\
\hline 3 & Control & 0.054149 & $0.000018^{*}$ & \\
\hline
\end{tabular}

Table 6. Scheffe Test. Assessment of pain in the second stage of
labor in primiparas
\begin{tabular}{|c|c|c|c|c|}
\hline & Group & $\{1\}$ & $\{2\}$ & $\{3\}$ \\
\hline 1 & TENS & & 0.122520 & 0.321773 \\
\hline 2 & Immersion & 0.122520 & & 0.907570 \\
\hline 3 & Control & 0.321773 & 0.907570 & \\
\hline
\end{tabular}


cological agents. It is also important to educate woman about non-pharmacological pain relief methods in labour to help them to decide howtheir delivery should proceed [13].

Research on the effect of TENS stimulation applied during labour has been going on since $1977[14,15]$. Since then, researchers have proposed several different methods for arranging electrodes on the body of a woman giving birth. Some authors recommend placing four electrodes from the very beginning of delivery until the end $[14,16]$. One paper gave an example of 1 pair of electrodes that was placed between Th10 and S2 [9]. Our own study showed a statistically significant difference in pain at cervix dilation of 3 fingers, when women who used TENS during childbirth rated pain as less than those in the control group. There were no differences in the assessment of pain between TENS and control groups in the second period of delivery. Other studies also indicated a significant reduction in labour pain [11].

The most likely reason for this is the inadequate methodology of the procedure in the second period. It is consistent with the theoretical assumptions but does not work in practice. To obtain the full effect of the current you must constantly feel the maximum, painless tingling or shock caused by electrostimulation. When delivering, women often forget to adjust the current and change programs. Therefore, during the second period of labour, it seems practical to set the electrostimulator on a conventional program and set the maximum unbearable current and maintain it throughout the whole course of the second period of labour. Changingprograms of the device unnecessarily distracts women from the tasks they must perform when pushing.

Some of the delivering women noticedthat using the electrostimulator distracted their attention from pain and helped them concentrate on breathing.

Perhaps the lack of knowledge about TENS, as well as its unreliability, increases the stress of being in hospital and giving birth to the first child. The need for additional research in this field is worth noting.

Our research shows that the use of water immersion reduces labour pain during dilation of 4 fingers.

Water immersion is not offered in all hospitals, because of the lack of a bathtub. Often, only a shower is available, which does not give exactly the same effects as water immersion. Relaxation in the shower is also often limited by the number of showers available in delivery rooms.

In futurethe positive effect of water immersion should be considered in designing delivery rooms andsupplying the delivery rooms with bathtubs. TENS stimulation is shown to have a similar effect to water immersion. Both non-pharmacological methods significantly reduce labour pain [13]. However, there are many advantages of using TENS stimulation. It is a simple, non-invasive, non-pharmacological, inexpensive, free of side effects method which gives satisfaction in useand can be used during delivery [12]. Its beneficial effects are maintained throughout labour. A particularly important advantage is the possibility of using electrostimulation from the very beginning of delivery, when the woman is still at home. In the case of water immersion, the analgesic effect is mainly apparentduring the immersion. In addition, the size of the electrostimulator allows it to be used in even the smallest delivery room and it can be operated by the patient. Considering the above arguments, it may be necessary to consider increasing the popularity of transcutaneous electrical nerve stimulation in delivery rooms.

\section{CONCLUSIONS}

TENS stimulation and water immersion are good methods for dealing with labour pain and are especially helpful during the first period of labour.

TENS stimulation and water immersion are alternative, non-pharmacological methods for reducing labour pain, safe for both mother and child.

Thanks to TENS stimulation and water immersion, primiparas can have less painful childbirth.

\section{Acknowledgemnets}

We would like to thank the employees of the Obstetrics Clinic of the Medical University of Gdańsk and the obstetrics department of the Puck Hospital for substantial support during the researchand for making it possible to complete it.

The research was carried out with the support of the fund from the Medical University of Gdansk grant no. MN-20.

\section{Conflict of interest}

None.

\section{REFERENCES}

1. Cowan E, Heale R, Horrigan J, et al. Hydrotherapy as a Nursing Intervention for Labour Pain. Diversity of Research in Health Journal. 2017; 1: 121-132, doi: 10.28984/drhj.v1i0.10.

2. Brooks EJ. Water birth: using water as a comfort measure in labor. Int J Childbirth Educ. 2018; 3(1): 30-34.

3. Rusthon DN. Electrical stimulation in the treatment of pain. Disabil Rehabil. 2002; 24(8): 407-416.

4. Melzack R, Wall P.Tajemnica bólu. Kraków (PL)Wydawnictwo WAM.;2006

5. Woldriczek J. Patofizjologia bólu receptorowego. Nowa Klin. 2000; 7(9): 917-923.

6. Woodward J, Kelly SM. A pilot study for a randomised controlled trial of waterbirth versus land birth. BJOG. 2004; 111 (6): 537-545, doi: 10.1111/j. 1471-0528.2004.00132.x, indexed in Pubmed: 15198780.

7. Bączyk G, Cybulska V, Koźlak V, et al. Poziom lęku przedporodowego u kobiet w ciąży. Probl Hig Epidemiol. 2011; 92(4): 774-777.

8. Poręba R, Sioma - Markowska U, Poręba A. Poród w ujęciu interdyscyplinarnym. Perina-tol Neonatol Ginekol. 2008; 1(2): 149-151.

9. Kaplan B, Rabinerson D, Lurie $S$, et al. Transcutaneous electrical nerve stimulation (TENS) for adjuvant pain-relief during labor and delivery. Int J Gynaecol Obstet. 1998; 60(3): 251-255, doi: 10.1016/s00207292(97)00275-0, indexed in Pubmed: 9544709.

10. Spank JTv, Cambier DC, Paepe HDe, et al. Pain relief in labour by transcutaneous electrical nerve stimulation (TENS). Archives of Gynecology and Obstetrics. 2000; 264(3): 131-136, doi: 10.1007/s004040000099. 
11. Báez-Suárez A, Martín-Castillo E, García-Andújar J, et al. Evaluation of different doses of transcutaneous nerve stimulation for pain relief during labour: a randomized controlled trial. Trials. 2018; 19(1): 652, doi: 10.1186/s13063-018-3036-2, indexed in Pubmed: 30477529.

12. Suárez AB, Castillo EM, Andujar JG, et al. Satisfaction in the management of pain during labour with the use of transcutaneous nerve stimulation. Annals of Physical and Rehabilitation Medicine. 2018; 61: e476, doi: 10.1016/j.rehab.2018.05.1111.

13. Czech I, Fuchs P, Fuchs A, et al. Pharmacological and Non-Pharmacological Methods of Labour Pain Relief-Establishment of Effectiveness and Comparison. Int J Environ Res Public Health. 2018; 15(12), doi: 10.3390/ijerph15122792, indexed in Pubmed: 30544878.
14. Shahoei $R$, Shahghebi S, Rezaei M, et al. The effect of transcutaneous electrical nerve stimulation on the severity of labor pain among nulliparous women: A clinical trial. Complement Ther Clin Pract. 2017; 28: 176-180, doi: 10.1016/j.ctcp.2017.05.004, indexed in Pubmed: 28779926.

15. Augustinsson $L E$, Bohlin $P$, Bundsen $P$, et al. Pain relief during delivery by transcutaneous electrical nerve stimulation. Pain. 1977; 4(1): 59-65, doi: 10.1016/0304-3959(77)90087-2, indexed in Pubmed: 927881.

16. Santana LS, Gallo RB, Ferreira $\mathrm{CH}$, et al. Transcutaneous electrical nerve stimulation (TENS) reduces pain and postpones the need for pharmacological analgesia during labour: a randomised trial. J Physiother. 2016; 62(1): 29-34, doi: 10.1016/j.jphys.2015.11.002, indexed in Pubmed: 26701166. 